\title{
National Unmanned Aircraft Systems Project Office
}

\section{Who We are}

The U.S. Geological Survey (USGS) National Unmanned Aircraft Systems (UAS) Project Office leads the implementation of UAS technology in the Department of the Interior (DOI). Our mission is to support the transition of UAS into DOI as a new cost-effective tool for collecting remote-sensing data to monitor environmental conditions, respond to natural hazards, recognize the consequences and benefits of land and climate change and conduct wildlife inventories. The USGS is teaming with all DOI agencies and academia as well as local, State, and Tribal governments with guidance from the Federal Aviation Administration and the DOI Office of Aviation Services (OAS) to lead the safe, efficient, costeffective and leading-edge adoption of UAS technology into the scientific research and operational activities of the DOI.

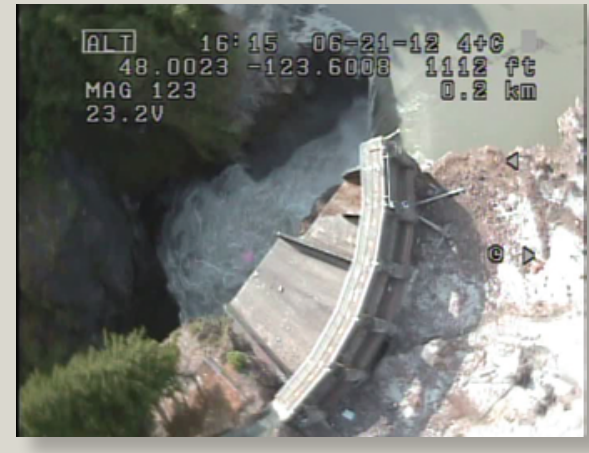

Unmanned Aircraft Systems (UAS) imagery over Glines Canyon Dam, Olympic National Park, Wash.

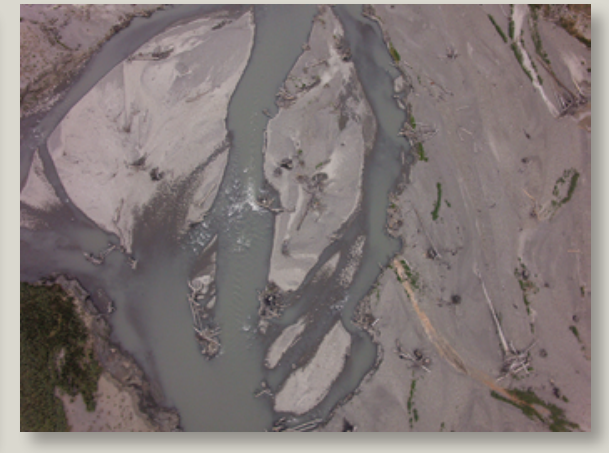

River flow and sediment transport after dam removal, Olympic National Park, Wash.

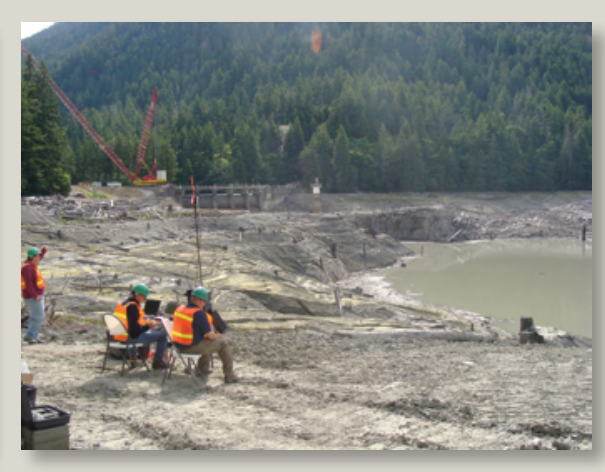

UAS ground operations at Glines Canyon Dam, Olympic National Park, Wash.

The USGS, Bureau of Reclamation, and the National Park Service explored the potential use of UAS technology at Lake Aldwell along the Elwha River in Olympic National Park, Washington, to monitor fish, river sediment, and vegetation changes during one of the largest dam removals and controlled sediment releases in North American history.

\section{What We Provide}

- Supply geospatial products for use in geographic and scientific analysis

- Guide coordination between the Federal Aviation Administration and the OAS for approval to collect data while operating in the U.S. National Airspace

- Support UAS flight operations

- Recommend project-specific sensor types and UAS platform selections

- Assist efficient UAS flight planning and logistical support

- Assist data processing using a variety of cutting-edge software tools

- Develop new geospatial products that meet the needs of DOI scientists

Photograph at top of page: Haleakala National Park, Hi.

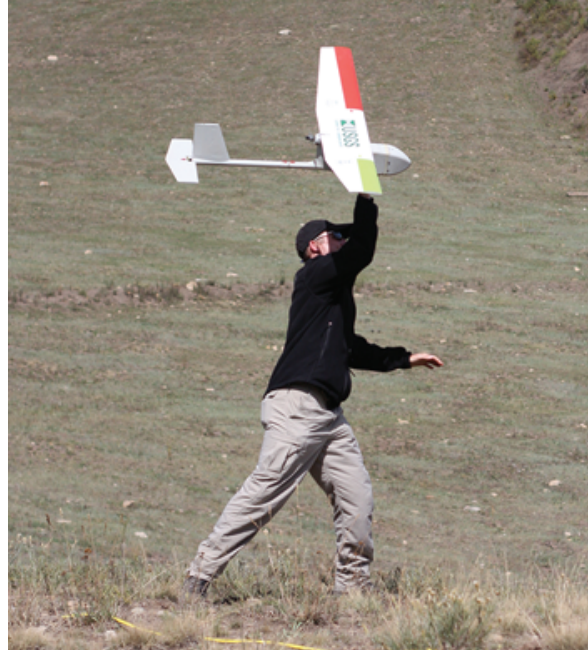

Unmanned Aircraft Systems operator hand launching Raven A. 


\section{Derived Data Products We Produce}

The USGS National UAS Project Office provides geospatial data products and support for cooperators that require assistance with deriving useful products from UAS data acquisitions. The UAS Project Office uses state-of-the-art computer vision three-dimensional (3D) modeling techniques and traditional geospatial product-creation methods to provide new ways of rapidly creating geospatially accurate data.

- Point Cloud generation

- Digital Surface Models (DSM)

- Color infrared orthophotography

- Keyhole Markup Language (KML)

- 3D modeling
- Contour map generation

- Volumetric measurements

- Normalized Difference Vegetation Index (NDVI)

- Feature extraction

- Orthophotography

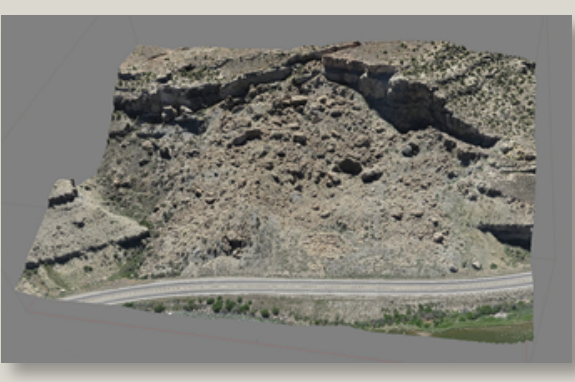

Point Cloud 3D model of the DeBeque Canyon landslide, western Colo.

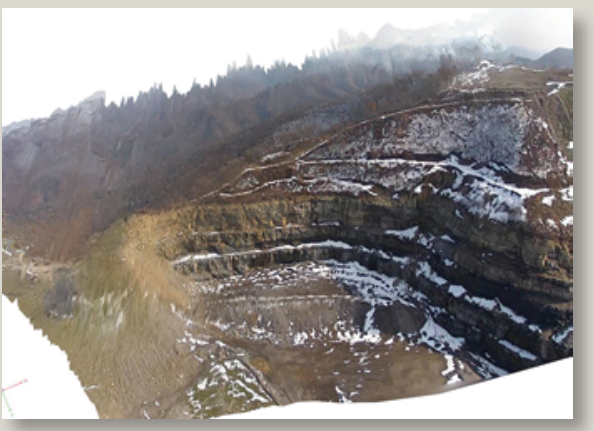

3D model of a coal mine headwall, central W. Va.

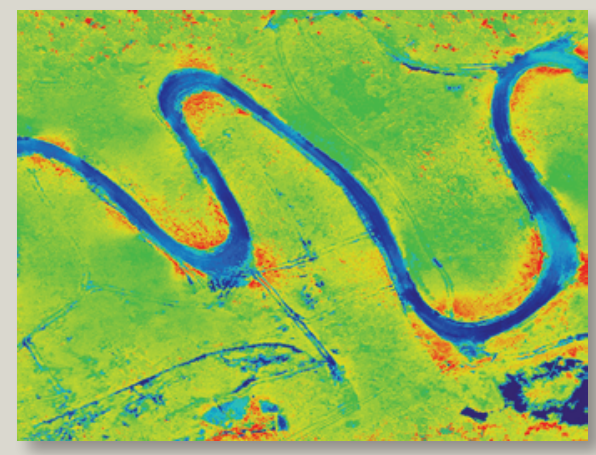

Color Infrared of Normalized Difference Vegetation Index over open coal mining area, central W. Va.

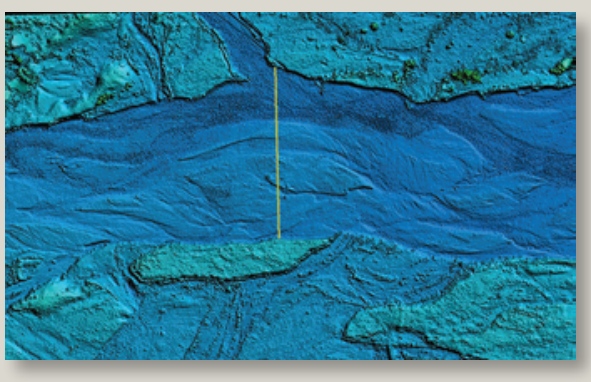

Digital Surface Model of Platte River, central Nebr.

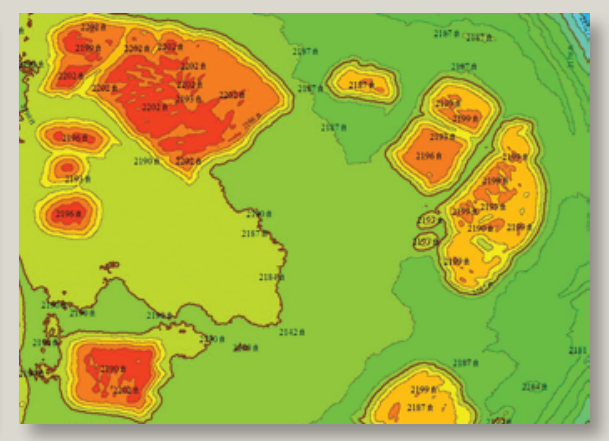

3-foot contour map of mining stockpiles, eastern Ky.

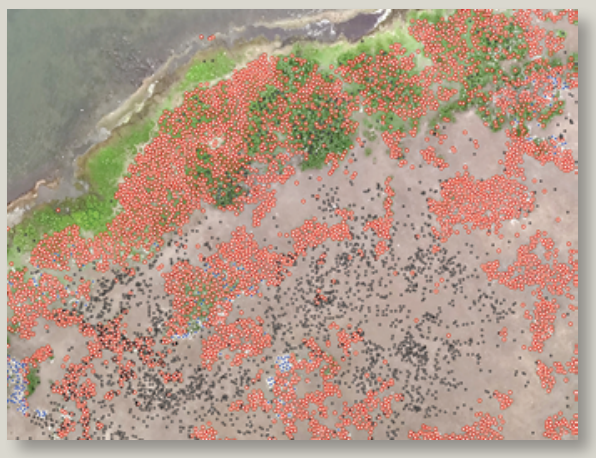

Feature extraction of nesting White Pelicans at Chase Lake National Wildlife Refuge, N. Dak.

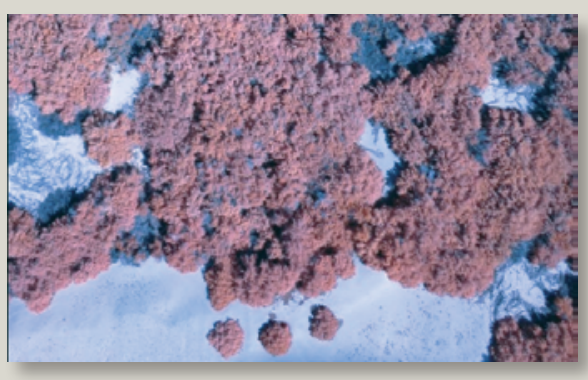

Color infrared image of Havasu National Wildlife Refuge, Ariz.

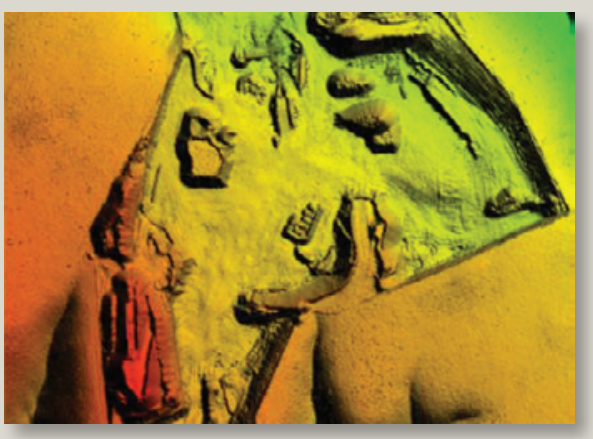

Volumetric calculations of mining area, western Colo.

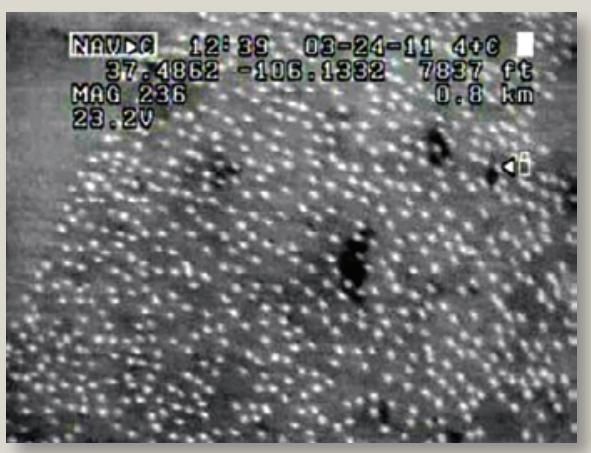

Infrared thermal imagery of Sandhill Crane roost at Monte Vista National Wildlife Refuge, Colo.

All images courtesy of the National Unmanned Aircraft Systems Project Office.

Learn more about the USGS UAS Project Office online: http://uas.usgs.gov

Denver Federal Center, Building 25, Denver, Colorado 80225-0046 